\title{
La expresión de la dualidad y el tema del doble en las prime- ras versiones francesas del Tristán: entre la verdad y la men- tira o el juego de la puesta en escena
}

\author{
Ramón GARCÍA PRADAS \\ Universidad de Castilla-La Mancha
}

No son pocos los estudios que se han llevado a cabo en torno a las diferentes versiones que a lo largo de los tiempos se han realizado acerca de la célebre leyenda de amor, fatalidad y muerte de Tristán e Iseo y, sin embargo, pese a todos estos estudios, que han venido a cubrir aspectos muy diversos tales como los orígenes del mito ${ }^{1}$, las relaciones de intertextualidad que ha suscitado ${ }^{2}$, su incursión en otras literaturas ${ }^{3}$, el tema del amor ${ }^{4}$, entre un largo etcétera, uno de las temas más enigmáticos, el de la dualidad, parece no haber suscitado demasiado interés entre la crítica. Pretendemos con este artículo, por tanto, arrojar un haz de luz que sirva para entender cómo dicho tema, el de la dualidad y la expresión del doble, se articula en las primeras versiones francesas del Tristán; nos referimos a la versión de Béroul, tradicionalmente calificada como versión épica o común, a la versión de Thomas d'Angleterre, también llamada por la crítica versión lírica o

1 A. VARVARO, "La teoria del l'archetipo tristaniano", Romania, 88, 1967, 13-58; G. SCHOEPPERLE, Tristan and Isolt: A Study of the Sources of the Romance, Nueva York (Universidad de Nueva York) 1970; E. BAUMGARTNER, De la légende aux récits en vers, Paris (PUF) 1987; M $^{a}$.L. CUESTA TORRE, "Origen de la materia tristaniana: estado de la cuestión”, Revista de Estudios Humanísticos: Filología 13, 1991, 185-197; J. COCHEYRAS, Tristan et Yseut: genèse d'un mythe littéraire, París (Honoré Champion) 1996; R. GARCÍA PRADAS, "Fuentes y elementos célticos en los Tristán de la Edad Media", Estudios de Filología Moderna 3, 2002, 29-43.

${ }^{2}$ M. DELBOUILLE, "Le premier roman de Tristan", Cahiers de Civilisation Médiévale V, pp.273-286 y 419-434; M.R. BLAKESLEE, Identity, Intertextuality and Meaning in the Old French Tristan Poems, Cambridge (D. S. Brewer) 1989.

${ }^{3}$ J. CLUZEL, "Les plus anciens troubadours et la légende amoureuse de Tristan et Yseut", Mélanges Istvan Frank 1957, pp.155-169; M. DELBOUILLE, "Cercamon n'a pas connu Tristan", Studi in onore di Angelo Monteverdi, 1959, pp.198-206; E. WEAVER, "Tristan Studies in Italy: a Review of Current Scholarship", Tristania IV, $\mathrm{n}^{\circ}$ 1, 1978 pp.3-14; F. Campa, "The Spanish Tristan: State of Research and New Directions", en Tristania, III n ${ }^{\circ}$ 2, 1978, 36-45; H. SHARRER, "Malory and the Spanish \& Italian Tristan Texts: the Search for the Missing Link", Tristania IV n 2, 1979, 3643; $\mathrm{M}^{\mathrm{a}} \mathrm{L}$. CUESTA TORRE, Aventuras amorosas y caballerescas en las novelas de Tristán, León, Servicio de Publicaciones de la Universidad de León, 1994.

${ }^{4}$ D. de ROUGEMONT, L'amour et l'occident, París (10/18) 1972; C.C. ADAM, Tristan et Yseut: la pasión amoureuse, París (Ellypses) 1991; C. SAHEL, Esthétique de l'amour: Tristan et Yseut, Montreal (L'Harmattan) 1999. 


\section{Daniel Grégorio}

cortés, y a las versiones episódicas de las Folies Tristan de Berne y Oxford, ya que es en ellas donde mejor, y con mayor complejidad y riqueza, se articula el tema que supone el objeto de estudio del presente trabajo. Ello no quiere decir, sin embargo, que en algún momento no nos vayamos a ver sustraídos de hacer mención de otras versiones medievales como las de los alemanes Eilhart von Oberg y Gottfried von Strassbourg.

Desde luego, y sea como fuere, la presencia de la dualidad a lo largo del Tristán es un hecho incuestionable que aparece de manera casi constante. Por ejemplo, dos son las mujeres que protagonizan la historia y las dos, precisamente, reciben el mismo nombre, Iseo. Para diferenciarlas los textos las apodan Iseo la Rubia e Iseo de las Blancas Manos, si bien es cierto que cuando Tristán conoce a la segunda, su nombre y su belleza le evocan a la primera y por ello únicamente decide tomarla como esposa, pues el amor no se ha dado ni se podrá dar entre ellos ${ }^{5}$. Asimismo, otro de los elementos que configuran el tema de la dualidad en la historia que nos ocupa y moviéndonos aún en el ámbito de los personajes, lo encontramos una vez más en la versión de Thomas, concretamente en el personaje de Tristán el Enano. Su nombre coincide con el personaje central de nuestra historia, pero la dualidad va aún más lejos si atendemos a lo que este personaje, que aparece una sola vez al final del relato, nos cuenta, pues, al igual que Tristán, Tristán el Enano es un hombre desgraciado en amores, ya que han raptado a la mujer a la que ama. Desde entonces, sus únicos sentimientos son la soledad, la amargura y la infelicidad al no poder tener en sus brazos a la mujer amada. No es difícil percatarse que básicamente éste es el núcleo que constituye el drama tristaniano. En efecto, Tristán sufre por no poder estar junto a Iseo, pues ella vive condenada junto a Marco, a quien pertenece legítimamente por ser su esposa. El personaje de Tristán el Enano es, pues, casi un doble de Tristán, un espejo en el que nuestro protagonista puede verse reconocido no sólo en el nombre. De hecho, si Tristán el Enano ha acudido a pedir ayuda a Tristán es precisamente porque, como nos dice Thomas, él mejor que nadie puede comprender su estado de desgracia y abatimiento al haber perdido también a la mujer a la que ama. De hecho, cuando

${ }^{5}$ A este respecto, la versión de Thomas nos dice: Le nun, la belté la rëne / Nota Tristans en la meschina: / Pur le nun prendre ne la volt, / Ne pur belté, ne fust Ysolt. / Ne fust Ysolt apelee, / ja Tristrans ne l'oüst amée; / Se la belté Ysolt n'oüst, / Tristan amer ne la poüst: / Pur le num e pur la belté / Que Tristrans en li a trové, I Chiet en decir e en voleir. / Que la meschine volt aveir, J-C. PAYEN, Tristan et Yseut, París (Bordas) 1989, p.154. 
Tristán le dice que le ayudará, pero le pide un tiempo para hacerlo, Tristán el Enano le reprocha que, si en verdad fuese Tristán, se habría identificado hasta tal punto con su desgracia que, de inmediato, habría decidido ayudarlo:

\author{
(... Parfei, amis, \\ Vus n'estes cil que tant a pris! \\ Jo sai que si Tristran fuisset, \\ La dolur quë ai sentisset, \\ Car Tristran si ad amé tant \\ Qu'il set ben quel mal unt amant. \\ Si Tristran oüt ma dolur, \\ Il m'aidast a icel amur: \\ Itel peine n'itel pesance \\ Ne metreit pas en perlungance . $^{6}$
}

No son éstos, ni mucho menos, los únicos elementos de dualidad que podemos destacar. Por ejemplo, bien podríamos hacer mención de la reduplicación en el renacimiento del héroe. Primeramente herido por Moroldo con una lanza envenenada y después por un dragón contra el que ha de combatir para conseguir la mano de Iseo, es salvado en sendas ocasiones gracias a los ungüentos mágicos que le proporcionan la reina y su hija. Sin embargo, dado que es Tristán precisamente quien ha acabado con la vida de Moroldo, el amado tío de Iseo, se ve obligado a ocultar su verdadera identidad haciéndose pasar por juglar y alterando el orden de las dos sílabas que constituyen su nombre -ahora se llamará Tantris- para no ser descubierto y condenado a muerte en Irlanda. A partir de este momento, nuestro personaje se verá envuelto en un juego de máscaras y disfraces que nos introducen en el tema del doble, objeto de trabajo de este artículo, en el que siendo otro en apariencia, ya sea como mendigo, como loco o como leproso, Tristán puede, paradójicamente, ser él mismo y decir así cuanto siente de cara a la sociedad. Estas puestas en escena permiten a Tristán y, en general, a los amantes, en un contexto en el que la verdad y la mentira se confunden o en el que, mejor dicho, la verdad se dice hábilmente en términos de mentira y la mentira en términos de verdad, jugando con el referente y la palabra y la relación que entre ambos existe, gozar libremente de su amor, sin soportar el peso de la censura social que continuamente les instiga a la separación y a la desgracia.

${ }^{6}$ Thomas d'Angleterre, Op.cit., p.217. 


\section{Daniel Grégorio}

Podríamos añadir muchos otros elementos de dualidad en unos relatos que parecen estar configurados mediante un juego de espejos en el que el texto continuamente se remite a sí mismo. Por ejemplo, haciendo nuevamente mención a la versión de Thomas, podríamos dar cuenta de la escena de la Sala de las Imágenes, sala que Tristán, exiliado en Bretaña, ha mandado construir con estatuas de mármol que reflejen sus momentos de amor con la reina Iseo. En ella Tristán habla con las estatuas y se deleita con ellas, proyectando la realidad hacia un mundo fícticio en el que sólo parece tener cabida el amor de los amantes.

Muy en consonancia con esta última idea puede estar otro de los elementos que constituyen el tema de la dualidad en la historia que nos ocupa. Nos referimos a los relatos de amor, a los lais que los propios amantes componen en ausencia el uno del otro para poder aliviar así el amargo dolor que les causa la distancia y la separación. En ellos prácticamente nos cuentan su propia historia, convirtiéndose estos pequeños textos en un relato dentro del relato en el que el juego de espejos del que hablábamos anteriormente parece, si cabe, cobrar mayor sentido.

Sin embargo, no conviene extenderse más, básicamente por cuestiones de espacio, en estos elementos de dualidad porque la que nosotros pretendemos estudiar es la dualidad que se desprende del lenguaje de la obra, la que se establece entre la verdad y la mentira, la que se origina como producto de las cuantiosas y graciosas, al tiempo que inteligentes puestas en escena de los amantes, en las que Tristán e Iseo se convierten en actores que dentro del relato representan su propio papel a fin de confundir, diciendo al mismo tiempo la verdad a todos aquellos que se oponen y censuran su amor y principalmente al rey Marco, máximo oponente de la pasión ilegítima de Tristán e Iseo en tanto que esposo de la joven. Ello convierte a Marco, como muy bien apunta Robert, en un personaje constantemente sumergido en la duda, que lo único que hace es escuchar y adherirse momentáneamente a lo que unos y otros, ora sean los amantes ora sean los felones de Cornualles, le dicen: Un personnage comme Marc, incapable de se fixer à une vérité stable, balance ainsi sans cesse entre deux paroles concurrentes, prêt à tomber dans tous les pièges, à adhérer à tous les discours qu'on lui tend. Que faire, en effet, quand plus rien n'est vrai, sinon se rattacher à des paroles? ${ }^{7}$.

\footnotetext{
${ }^{7}$ R. ROBERT, Premières leçons sur le mythe de Tristan, Paris (PUF) 2000,
} p.80. 


\section{La expresión de la dualidad y el tema del}

Precisamente, la versión de Béroul se inaugura, de manera azarosa, por supuesto, ya que el texto podría haber quedado fragmentado en cualquier otro momento de la historia, con una escena, la que corresponde a la cita espiada de los amantes, en la que Tristán e Iseo, habiéndose percatado, gracias a la imagen que ha quedado reflejada en el agua de una fuente, de que Marco los está espiando encaramado en lo alto de un pino $^{8}$, empiezan a justificar su conducta a fin de hacer ver a Marco su inocencia. Llegados a este punto, hemos de suponer que los amantes son conscientes de que el rey, cuando menos, ha de tener sospechas de su idilio amoroso. Así lo deja ver la propia Iseo cuando pide encarecidamente a Tristán que no la vuelva a citar en privado, pues, habida cuenta de lo que se está diciendo de ellos, tal situación, si llegara a oídos del rey, sólo podría servir para despertar aún más su cólera, pero precisamente la conversación está llegando a oídos del rey y los amantes lo saben y, además, conscientemente lo pretenden. No en vano Bar apunta con no poca razón que, a la luz de lo dicho, el verdadero destinatario del discurso de Iseo no es Tristán, como ella quiere dejar ver, o mejor dicho, hacer creer, sino el propio rey Marco, quien, escondido en el árbol y sin saber que los amantes lo han descubierto, escucha su conversación y sus razonamientos con gran interés: On sait qu'Iseut, près de la fontaine où elle a distingué l'ombre du roi Marc, comme on aurait dit autrefois -son reflet, comme nous dirions plus volontiers- justifie sa conduite en des termes qui sont censés s'adresser à Tristan, son interlocuteur bien visible, et qui sont destinés en fait à l'époux caché dans l'arbre dominant le bassin'.

Iseo da, pues, toda clase de pruebas de su inocencia y para que su discurso no lo haya dicho en balde, alude además a aquellos motivos por los que Marco debe estar agradecido a Tristán. Hace así mención, por ejemplo, de cómo Tristán luchó valerosamente contra Moroldo para defender a Marco y a todo el reino de Cornualles de las injustas exigencias del gigante. Asimismo, la alusión al episodio del Moroldo

\footnotetext{
${ }^{8}$ De esta redistribución en la que lo alto entra en contraste con lo bajo y en la que se proyecta un plano de inversión con la sombra de Marco reflejada en el agua da cuenta Giddey en un completo artículo en el que aborda la distribución espacial en torno a los conceptos de alto y bajo en el Tristán de Béroul: Le Tristan de Béroul s'ouvre sur une scène spectaculaire dans sa répartition du haut et du bas. Le roi Marc s'est placé dans un pin, au-dessus de Tristan et d'Iseut, afin d'épier leur rendez-vous. L'ombre qu'il projette dans l'eau de la fontaine préviendra les amants, qui, ainsi, pourront le berner, J. L. GIDDEY, "Le Haut et le bas dans le Tristan de Béroul", Tristania IX, no 1 y 2, p.17.

${ }^{9}$ F. BAR, "Le premier segment ambigu d'Iseut dans le poème de Béroul", Bulletin Bibliographique de la Société Internationale Arthurienne XXIX, 1977, 181.
} 


\section{Daniel Grégorio}

le viene muy bien a la reina para recordar a Marco que en aquel momento nadie quiso defenderlo y ello no nos parece en modo alguno gratuito, ya que, indirectamente, pero de la forma más eficaz que puede, la reina está desacreditando a aquellos que se oponen a su amor con Tristán, desvelando su relación adúltera al rey, pues ellos fueron los primeros en no querer participar en el combate contra Moroldo. La astucia de Iseo, que en todo momento y con no poca maestría dirige el discurso, resulta, desde luego, incuestionable. Cada vez más sabe meterse en su papel de víctima, representando una auténtica puesta en escena que no tardará en dar sus frutos. Así, finge incluso estar contrariada con Tristán, reclamándole que no vuelva a comprometerla en una cita clandestina. Afirma amarlo, cosa que es muy cierta, para que Marco lo escuche, pero inmediatamente justifica este amor al ser Tristán pariente de su marido y al ser, por tanto, este amor una cuestión de deber más que otra cosa. Iseo, entre tanto, sigue haciéndose la víctima de las acusaciones que recibe y se puede decir así que su puesta en escena va en aumento hasta el punto de hacer que su parlamento torne en un auténtico juramento de inocencia, aspecto que se hace constatable casi desde el principio del discurso de la reina cuando nos dice:

\section{Mais Dex plevist ma loiauté Qui sor mon cors mete flaele, S'onques fors cil qui m'ot pucele Out m'amistié encor nul jor! ${ }^{10}$.}

Por una parte, con estas palabras Iseo miente y, por otra, dice al mismo tiempo la verdad. Miente porque el rey Marco no la ha tenido virgen, pero a los ojos de él dice la verdad, ya que para que Marco no se diera cuenta de que Iseo ya había perdido la virginidad, decide, junto a Tristán, que su fiel sirvienta Brangien la sustituya la noche de bodas en el lecho nupcial en el que la aguarda Marco. El rey, que, en su momento no se percata del cambio, piensa, pues, que ha tomado a su mujer virgen. Por otra parte, si hemos dicho que en el ensamblaje de su discurso Iseo está buscando que Marco sea el receptor del mismo, pensamos que las palabras que anteriormente hemos citado no están verdaderamente dirigidas a Marco sino a Tristán. Él es quien ha gozado de su virginidad y sólo él es su amante. Evidentemente, el hecho de desposarse no cabría tanto entenderlo como un ceremonial re-

\footnotetext{
${ }^{10}$ BEROUL, Op.cit., pp.14-16.
} 
ligioso sino como la primera experiencia de amor vivida por los dos amantes.

Como puede fácilmente apreciarse, la reina, en su puesta en escena, sigue un juego de verdades y mentiras con el único fin de confundir al destinatario del mensaje. Tristán, que no ha tardado mucho en percatarse de la ingeniosa treta, pronto seguirá el juego de Iseo, pidiéndole encarecidamente que interceda por él ante el rey, pero Iseo, que no busca otra cosa que mostrarse ante los ojos de su marido como esposa firme, estoica y fiel, niega repetidas veces a Tristán tal favor.

Los amantes se despiden y Marco, que ha escuchado con interés todo el encuentro, termina convencido de la inocencia de los amantes, pensando así que éstos dicen la verdad, mientras que aquel que verdaderamente se la ha dicho, el odioso enano de Tintagel, como el propio narrador lo califica, lo ve como a un vil mentiroso con el que es preciso acabar. Marco es así, como ya decíamos en un principio, un personaje voluble cuyo punto de vista no tarda en cambiar en función de quién sea su interlocutor y en función, también, del discurso que escuche. Veamos así cómo reacciona contra el enano de Tintagel:

\author{
... Li rois qui sus en l'arbre estoit \\ Out l'asenblee bien veüe \\ Et la raison tote entendue. \\ De la pitié qu'au cor li prist, \\ Qu'il ne plorast ne se tenist \\ Por nul avoir; mout a grant duel. \\ Mot het le nain de Tintagel. \\ Las, fait li rois, or aï veü \\ Que li nains m'a trop deceü. \\ En cest arbre me fist monter. \\ Il ne me pout plus ahonter. \\ De mon nevo me fist entendre \\ Mençonge por quoi ferai prendre. \\ Por ce me fist metre en aïr, \\ De ma mollier faire haïr. \\ Je l'en crus, et si je fis que fous. \\ Li guerredons l'en sera sous. \\ Se je le puis as poinz tenir, \\ Parfeu ferai son cors fenir ${ }^{11}$.
}

\footnotetext{
${ }^{11}$ BÉROUL, Op.cit., pp.10.
} 


\section{Daniel Grégorio}

Sin embargo, no es en la versión de Béroul el único momento en que los amantes llevan a cabo una cuidada puesta en escena en la que la mentira logra disfrazarse de verdad con una habilidad y una astucia que nos muestran a Tristán e Iseo como lo que son, como dos verdaderos actores capaces de desdoblar su personalidad para librar toda serie de obstáculos a la hora de defender su amor, aspecto que, dicho sea de paso, se hará especialmente notorio en el caso de Tristán al recurrir continuamente al disfraz y a la máscara con objeto de desdoblarse para tener paradójicamente la oportunidad de ser él mismo y para poder disfrutar de aquello que la sociedad le prohíbe. El tema del doble y de la dualidad, que ya acabamos de ver en la escena de la cita espiada y que se va a reforzar mucho más en Béroul con el juramento de la Blanca Landa, escena que no tardaremos en comentar, se encuentra en multitud de aspectos de la historia tristaniana. Por ejemplo, el que el agua actúe como espejo para favorecer a los amantes podría ser uno de ellos. De hecho, empezábamos este artículo aludiendo a aquellos aspectos de dualidad que resultaban más significativos (presencia de Iseo la Rubia e Iseo de las Blancas Manos, Tristán el Enamorado y Tristán el Enano, etc.). Por ejemplo, la idea de pasión trágica y fatal, tema central de la leyenda, ya lo encontramos en la relación amorosa que mantienen los padres de Tristán ${ }^{12}$. Bien se podría decir entonces que existe una reduplicación de la biografía de estos personajes en su hijo y la relación que éste mantiene con Iseo, lo cual supone una reduplicación de la estructura que presenta la globalidad de la historia: $L a$ duplication de la structure, trait caractéristique des romans de Tristan, et qu'a repris Chrétien de Troyes dans Cligès, pourrait être aussi une première tentative de l'écriture romanesque pour élargir le temps de la fiction, pour créer un univers de papier à l'image de l'univers réel, dans lequel la destinée des êtres dépasse la durée propre de leur existence et s'explique par l'enchaînement passé des causes et des conséquences et par leurs indices sur le présent ${ }^{13}$.

De hecho, esta idea de reduplicación en la estructura de la historia se encuentra presente en la misma versión de Béroul, precisamente entre la cita espiada de los amantes, que ya hemos comentado, y el juramento de la Blanca Landa, al que con anterioridad hemos aludido y sobre el que habíamos prometido hablar más en profundidad. De hecho, y no en vano, Bar emparienta ambos episodios y prácticamente de forma simétrica los diferencia: le fameux serment de la Blanche

\footnotetext{
${ }^{12}$ Para conocer mejor este episodio, se pueden consultar las versiones alemanas de Eilhart von Oberg o Gottfried von Strassbourg.

${ }^{13}$ E. BAUMGARTNER, Tristan et Yseut, Paris (Ellypses), 2001, p.35.
} 
Lande présente avec la scène de la fontaine une ressemblance générale, et en même temps des différences qui opposent curieusement, terme à terme, les deux passages ${ }^{14}$.

Tras haberse transcurrido los tres años de duración del filtro, Tristán e Iseo se arrepienten de su conducta y piden perdón a Marco mediante una carta que hábilmente les redacta el ermitaño Ogrín. Marco decide perdonar a Iseo, quien regresa junto a su esposo con toda clase de fiestas y boatos. Tristán, en cambio, no tiene la misma suerte y debe partir en exilio al menos durante un año. Sin embargo, los barones, en su afán por hostigar a la reina, a la que ven como una extranjera, exigen al rey que pida a su esposa que se justifique en público mediante juramento que en todo momento ha sido fiel a su esposo o, de lo contrario, le declararán la guerra. Nuevamente siembran la duda en el rey y, aunque Marco está menos dispuesto a creerlos, temiendo sus amenazas, cuanta a Iseo todo lo sucedido. La reina, haciendo una vez más gala de su astucia y de su dominio de la palabra, acepta el reto impuesto por los barones felones, pero lo hace curándose en salud desde el primer momento al ser ella quien ponga las condiciones del juramento, lo cual hace que tal prueba, tanto en esta versión como en el resto de versiones en las que aparece (Sir Tristrem, Tristan Saga y versión de Gottfried), sea mucho más libre de lo que en un principio requería la costumbre judicial del momento ${ }^{15}$. La reina pide así tener garantes en este juicio para que la puedan defender, pues en Cornualles, tierra cuyos habitantes califica de mentirosos ${ }^{16}$, cuando paradójicamente la que miente es ella, todo parece estar contra su persona y todos parecen calumniarla. En este sentido, y con no poca astucia, hace mención explícita de los tres felones exigiendo que estén presentes en el juicio para que comprueben de una buena vez con sus propios ojos que es inocente. Para ello, reclama la presencia de Arturo y sus caballeros como garantes, ya que, además, en su fuero interno piensa que será una buena forma de intimidar a sus enemigos:

\section{A terme avrai en mié la place \\ Le roi Artur et sa mesnie. \\ Se devant lui sui alegie, \\ Qui me voudroit après sordire?}

${ }^{14}$ F. BAR, op.cit., p. 182.

${ }^{15}$ E. YORK, "Isolt's ordeal: English legal customs in the Medieval Tristan Legend", Studies in Philology LXVIII, n ${ }^{\circ} 1,1971$, p.4.

${ }^{16}$ En efecto, Iseo dice: Li Cornot sont reherceor, / De pluseurs evres tricheor, BÉROUL, Op.cit., 104. 
Daniel Grégorio

\author{
Cil me voudroient escondire, \\ Quë avront veü ma deraisne, \\ Vers un Cornot ou vers un Saisne? \\ Por ce m'est bel que cil i soient \\ Et mon deresne a lor eulz voient ${ }^{17}$.
}

Como podemos fácilmente apreciar, Iseo ha invertido en unos pocos instantes la situación. De haber sido acusada por los felones, pasa a ser ella quien los acusa, pero el juego de apariencias, mentiras y puestas en escena donde los amantes se convierten en verdaderos actores de un juego en el que la mentira se confunde con la verdad a través de los equívocos con los referentes no se queda aquí. Llega así el día de la ordalía judicial y a ella acude toda la corte de Marco, así como el rey Arturo y sus más nobles caballeros, pero Iseo también ha tomado la precaución de avisar a Tristán, quien, para entrar en escena, pierde su identidad para convertirse en un pobre leproso que ha acudido al evento con el único objeto de sacar unas cuantas monedas. Tristán representa a la perfección su papel, como el mejor de los actores. Se caracteriza físicamente hasta el punto de no poder ser reconocido ${ }^{18} \mathrm{y}$, sin embargo, en su caracterización, metafóricamente está diciendo mucho de sí mismo, ya que la lepra durante la Edad Media se asoció con el sexo o, para ser más específicos, con una conducta sexual desviada ${ }^{19}$ y precisamente de esta forma dice Tristán al rey haber contraído la lepra, ya que la mujer de la que se ha enamorado y con la que se ha acostado se la ha trasmitido.

\footnotetext{
${ }^{17}$ BÉROUL, Op.cit., p.103.
}

${ }^{18}$ El disfraz le permite no ser reconocido, pero al mismo tiempo da mayor credibilidad a su papel, ya que en la Edad Media era preciso que el leproso pudiera ser reconocido a través de su indumentaria de inmediato, dada la marginalidad y el rechazo que tal enfermedad provocaba (P.RICHARDS, The Medieval Leper and his Nothern Heirs, Cambridge (D.S. BREWER), 1977, p.124). No en vano, cuando Tristán reaparece en la corte de Marco ataviado de esta nueva guisa, no tarda mucho en recibir limosna, pero también golpes y bastonazos, sin que nadie, salvo la reina y el agudo Dinas, lo haya podido reconocer, pues tal es el empeño que Tristán ha puesto en disfrazarse, como nos dice Béroul en su versión: Vestu se fu de mainte guise. I Il fu en legne, sanz chemise. / De let burel furent les cotes / Et a quarreus furent ses botes. I Une chape de burel lee / Out fait tailler tote enfumee. / Affublez se fu forment bien: / Malade semble plus que rien, BÉROUL, Op.cit., p.113.

${ }^{19}$ En efecto, E.J. BURNS, "How lovers lie together: Identity and fictive discourse in the roman de Tristan", Tristania VIII, $\mathrm{n}^{\circ} 2$, pp.15-30, apunta en torno a la figura del leproso: The necessary association between lovers and lying in Béroul's Tristan is crystallized in the image of the leper, a figure used throughout the texte as a meaphore for sexual and linguistic deviance. 
Tristán es, pues, un buen actor. Al igual que Iseo, sabe jugar su papel con el lenguaje y con la ambigüedad que éste ofrece. También sabe elegir a sus personajes. Las elecciones no son, por tanto, gratuitas. Ciertos personajes como el loco, el mendigo o el leproso eran mal vistos socialmente, pero en la Edad Media también se practica, al menos en apariencia, lo que se llama la igualdad de almas. Así, el más poderoso, el rey en nuestro caso, se acerca al desfavorecido para ayudarlo y tratarlo como a un igual. Tristán lo sabe. Por ello pide encarecidamente limosna al rey Arturo, en primer lugar, y al rey Marco, posteriormente. De ambos recibirá entregada conversación y generosos dones, como manda el precepto anteriormente señalado.

Sin embargo, pese a que su puesta en escena sea mayor incluso que en el caso de Iseo, pues Tristán recurre constantemente a la máscara y al disfraz, hemos de decir que este desdoblamiento es lógico, debido, como bien señala Robert, a la alienación que, dicho sea de paso, la reina Iseo no conoce una vez que ha regresado con su esposo tras su estancia en el Morrois con Tristán: Cette aliénation coupe littéralement en deux la personnalité de Tristan. Elle crée en lui une fissure tragique, qui se manifeste notamment sous la figure du dédoublement. La profusion de doubles qui envahit le mythe atteste l'incapacité du héros à contenir son propre corps. Tristan ne se contrôle pas, ne se contient pas, sans doute parce qu'il n'est pas le seul hôte de son corps, investi par les désirs d'un autre. Sa personnalité éclate littéralement en plusieurs personnes qui n'ont de cesse que de lui imposer leur loi, leur vision de son identite ${ }^{20}$.

Vista, pues, la primera máscara de Tristán, su primer doble, que permite a nuestro protagonista mentir, pero decir la verdad al mismo tiempo, ya que al final de su parlamento, cuando está hablando con Marco, le confiesa que la mujer que le ha transmitido la lepra es la reina Iseo ${ }^{21} \mathrm{y}$ antes, incluso, llega a decirle que la enfermedad la padece desde hace tres años, precisamente el tiempo que ha durado su estancia con Iseo en el Morrois, no nos cabe la menor duda de que si ponemos en parangón la escena del escondit, más comúnmente conocida como el juramento de Iseo, con la puesta en escena que llevaran a cabo los amantes en la cita espiada, el escondit implica un claro crescendo de la escenificación, de la conciencia por parte de los amantes

${ }^{20}$ R. ROBERT, Op.cit., pp.75-76.

${ }^{21}$ Li roi li dit: 'Ne celez mie / Comment ce te donna t'amie. / -Dans rois, ses sires ert meseaus, / O lié faisoie mes joiaus: / Cist maus me prist de la comune. / Mais plus bele ne fu quë une ./- Qui est ele?-La bele Yseut. BÉROUL, Op.cit., pp.119-120. 


\section{Daniel Grégorio}

de estar jugando un papel en la obra. El escondit implica, como en definitiva nos dice Ollier, una teatralidad todavía más elaborada ${ }^{22}$.

Podemos decir que toda la escena ha sido premeditada y detalladamente preparada por Iseo desde el momento mismo en que se ve en el trance de jurar su inocencia. Acudiendo una vez más a su fiel sirviente Perinis, Iseo convoca a Tristán, quien deberá acudir disfrazado de leproso, así como a Arturo y a sus principales caballeros, que deberán actuar en calidad de garantes. La prueba comienza y Tristán acude vestido de leproso, como hemos dicho. Pide limosna y habla con el rey Arturo y con el rey Marco. Confiesa a Marco, también lo hemos señalado, ser el amante de la reina, pero su doble, su máscara le da aún mayor libertad cuando aparecen los tres felones. Es el momento que Tristán tiene para vengarse de ellos y así lo hace, aconsejándoles que atraviesen el Mal Paso por donde más fango hay. Los barones lo obedecen y no tardan, pues, en hundirse y enlodarse. Burlonamente, Tristán intenta ayudarles con su bastón para terminar, paradójicamente, hundiéndolos más en el fango, según él nos dice porque sus músculos están tan desgastados por la lepra que no controla sus movimientos. Una vez más, la puesta en escena permite reinvertir el mundo y el orden natural de las cosas. Al igual que Marco, encaramado en un árbol, ocupa una posición de altura privilegiada que le permite controlar la conversación de los amantes y pasa a ocupar una posición de inferioridad desde el momento en que éstos lo descubren reflejado en el agua de la fuente, los barones felones, que desde la marcha de Tristán han ocupado una posición superior, ejerciendo su poder sobre Marco y sobre los propios amantes al haberlos condenado a la separación por envidia, hundidos en el lodo y sumergidos por el bastón del leproso, pasan a ocupar una posición de inferioridad. Si teóricamente Iseo debía ser la juzgada en la prueba del juramento, en la práctica son ellos quienes están siendo castigados por quien indirecta, pero hábilmente ha sabido ejercer su rol de juez, el leproso, que no es otro que Tristán. Además, en este ajusticiamiento y en esa imagen de un mundo al revés, que el lector, así como el propio narrador, juzgan como más justo por la relación de simpatía que se ha generado con los amantes, las cosas van aún más lejos. En efecto, mientras que los barones, cuando salen del lodo, han de desnudarse en público, y el texto así lo apunta, no hemos de perder de vista que Tristán ha recibido como don, para que pueda abrigarse, las calzas del rey.

${ }^{22}$ M. L. OLLIER, "Le statut de la vérité et du mensonge dans le Tristan de Béroul”, en D. BUSCHINGER (ed.), La légende de Tristan au Moyen Âge, Göppingen (Kümmerle Verlag) 1987, p.299. 


\section{La expresión de la dualidad y el tema del}

Llegados a este punto, podríamos pensar que la teatralidad, así como la puesta en escena o el juego de la verdad y la mentira han llegado a su punto climático en el relato y, sin embargo, nada más lejos de la realidad, porque ésta aún está por venir y se encontrará precisamente en el juramento que lanza la reina Iseo para justificar su inocencia delante de los allí presentes. Si Tristán ha jugado hasta aquí con gran maestría su papel de actor, ahora le corresponde a la reina hacer lo mismo. Veamos con que astucia Iseo es capaz de no jurar en falso sin decir la verdad al mismo tiempo o diciéndola, pero creando conscientemente un equívoco de referentes, como, de forma distinta, eso sí, ya hiciera en la escena de la cita espiada.

Iseo parece ser conocedora de que en la Edad Media la justicia se basa esencialmente en lo que se $\mathrm{ve}^{23} \mathrm{y}$, por ello, prepara todo un espectáculo para los allí presentes. Habida cuenta de que no quiere manchar sus ricos vestidos con el lodo del fangal, pide a Tristán, es decir, al leproso, que la ayude a atravesar el Mal Paso subiéndola a su espalda. El leproso sigue el juego a la reina y la ayuda así a cruzar. Cuando han cruzado, éste continúa ejerciendo su papel y, al igual que hiciera con Marco y Arturo, pide a la reina limosna. La reina, en cambio, en una actitud altanera y llena de desprecio, se la niega, argumentando ante la vista de todo el mundo, pero especialmente dirigiéndose a Arturo y a su marido, que el leproso ya ha recibido suficientes dones allí como para darse un buen banquete. Tal espectáculo no provoca otra reacción que la risa de ambos reyes. Acto seguido, la reina pronuncia el juramento de no haber sido infiel a Marco. A priori, y no sin razón, podríamos pensar que la reina ha jurado en falso, pues en verdad Tristán es su amante y, por ende, no ha sido fiel al rey, al que ya engaña con Tristán incluso antes de haber contraído matrimonio. Sin embargo, la escena en la que Tristán ha ayudado a la reina a cruzar el Mal Paso no ha sido gratuita. Ni siquiera lo ha sido el guiño de humor de Iseo hacia el rey Marco, su marido, y hacia el rey Arturo. La puesta en escena tan graciosamente llevada a cabo por los dos amantes es mucho más que eso. Es, antes bien, el trampolín perfecto para que Iseo pueda emitir su juramento sin necesidad de mentir, pero sin necesidad tampoco de decir la verdad, ya que cuando jura, afirma tajante-

${ }^{23}$ Así lo afirma OLLIER, Op.cit., 300, cuando nos dice a tal respecto: La situation judiciaire idéale est alors celle de l'observation directe: celle du flagrant délit pour l'accusation, de la production au grand jour de la pièce à conviction pour la défense (...). La justice laïque médiévale est en effet singulièrement mutilante pour l'entendement humain; quand ne se produit pas l'adéquation évidente entre l'être et le paraître, seul Dieu peut déclarer le vrai, à la faveur là aussi d'un fait immédiatement observable. 


\title{
Daniel Grégorio
}

mente lo que allí todo el mundo ha podido ver (no olvidemos la relevancia de la visión en el ajusticiamiento durante la Edad Media), que entre sus piernas sólo ha estado su esposo y el leproso que la ha ayudado a cruzar el Mal Paso, lo cual es verdad porque este leproso es Tristán, su amante, e Iseo jamás ha estado con otro hombre que no haya sido su esposo, el rey, o el sobrino de éste, es decir, Tristán. Veamos, pues, en qué términos, con qué desafío y, sobre todo, con qué seguridad (la de no faltar a la verdad) con los Iseo hace su juramento:

\author{
- Seignors, fait el, por Dieu merci! \\ Saintes reliques voi ici. \\ Or escoutez que je ci jure, \\ De qoi le roi ci asseüre: \\ Si m'aït Dex et saint Ylaire, \\ Ces reliques, cest saintuaire, \\ Totes celes qui ci ne sont \\ Et tuit celes de par le mont, \\ Qu'entre mes cuisses n'entra home \\ Fors le ladre qui fist soi seme, \\ Qui me porta outre les guez, \\ Et li rois Marc mes esposez. \\ Ces deus ost de mon soirement, \\ Ge n'en ost plus de tote gent. \\ De deus ne me pus escondire: \\ Du ladre, du roi Marc mon sire. \\ Li ladres fu entre mes jambes ... ${ }^{24}$.
}

Tal conocimiento, que no es sino el producto de la escenificación de una perfecta actriz, no podrá provocar otra reacción que el asombro de todos los allí presentes, quienes después de haber visto lo que Iseo ha ratificado con sus palabras, quedan absolutamente convencidos de la inocencia de la reina y de la maldad de quien osa poner en tela de juicio su honor. Los felones, pues, nuevamente aparecen como mentirosos pese a ser ellos quienes dicen la verdad. En cierto modo, se repite la situación de la cita espiada cuando el enano Frocin había quedado ante los ojos del rey Marco como un auténtico mentiroso a pesar de haberle confesado la verdad, es decir, la relación adúltera de su sobrino y la reina Iseo. Veamos, pues, esta reacción de los allí presentes con la queda sancionada la puesta en escena de Iseo y Tristán:

\footnotetext{
${ }^{24}$ BEROUL, Op.cit., p.133.
} 


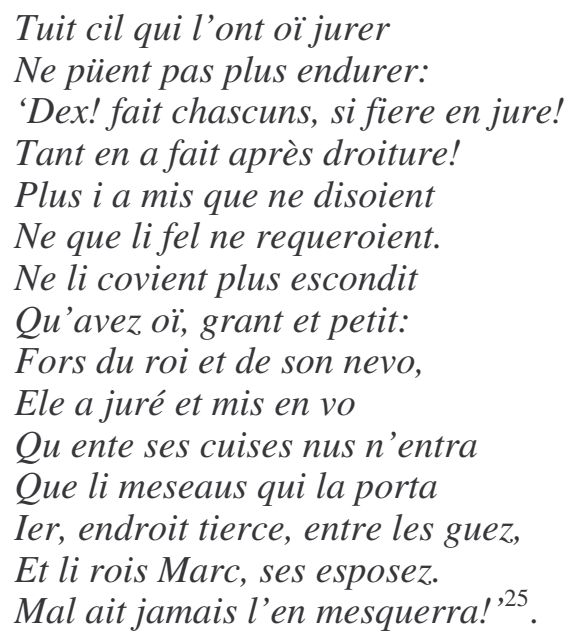

Acto seguido, será el propio rey Arturo quien ratifique la inocencia de la reina y la culpabilidad de los felones, de la que con anterioridad hemos dado cuenta, haciendo mención una vez más de la importancia de lo que allí se ha visto y oído, pese a que todo ello haya sido simplemente una hábil puesta en escena en la que Tristán se ha desdoblado para que la reina pudiera llevar a cabo el juego de referentes que tan airosamente le permite salvar la situación. La escena del escondit nos permite constatar cómo la verdad o, mejor dicho, las verdades son relativas y parciales. Para Ollier $^{26}$, en la versión de Béroul no se trata tanto de decir la verdad como sí de buscar el asentimiento del interlocutor, convencerlo e imponerle así una visión del mundo que, en el fondo, no es otra que la de los amantes desean, demostrar su inocencia para poder seguir encontrándose clandestinamente. De hecho, Marco, Arturo, Dinas, todo el pueblo de Cornualles e, incluso, el propio lector termina convencido de esta verdad, pues si Béroul intenta demostrar algo, es que la verdad no es única y en muchas ocasiones ni siquiera es bueno confesarla. De ahí que el ermitaño Ogrín, por ejemplo, es decir, aquel que ostenta los valores eclesiásticos, permita e, incluso, inste a los amantes a mentir en la carta que escriben a Marco para reconciliarse. Sobre esta noción tan relativa y subjetiva de la verdad y sobre su indisoluble relación con la mentira, nos gustaría tener en cuenta las palabras de Ollier, para quien la mentira o las diversas mentiras que nuestros amantes cuentan no son sino formas diversas de

\footnotetext{
${ }^{25}$ BEROUL, Op.cit., pp.133-134.

${ }^{26}$ M. L. Ollier, Op.cit., p. 299.
} 


\section{Daniel Grégorio}

decir la verdad: (...) toute vérité n'est pas bonne à dire, et certains mensonges sont bienfaisants -ou encore, même s'il importe peu dans notre perspective ici à dire en ces termes: la vérité n'est pas une à dire, et le mensonge n'est que la forme de cette diversité ${ }^{27}$.

El juego del doble y la mentira, o la verdad relativa, y la presencia de máscaras y disfraces que permiten a los personajes ocultarse, ser otros, ser alteridad dando cuenta de su propia identidad alterada ${ }^{28}$, del carácter dual o plural del ser humano, no sólo aparece en la imagen del leproso y en la escena del escondit en la versión de Béroul. El punto más álgido en el juego de dobles, de verdades y de mentiras y de puestas en escena aparece en los breves relatos anónimos que constituyen la Folie de Berna o la Folie de Oxford.

Ambos textos empiezan contándonos cómo Tristán sufre por encontrarse exiliado y sin tener la oportunidad de ver a la reina. Ello le provoca una sensación de pesar y dolor que no puede aguantar y que en ambos textos le incitará a la acción y a violar el pacto de no volver a la corte mientras dure su periodo de exilio. Sin embargo, para que su plan de encontrarse con la reina salga bien, una vez más es preciso que Tristán cambie de apariencia, que se desdoble, en definitiva, para protagonizar un nuevo papel, lo cual le permitirá nuevamente burlar a Marco y al resto de la corte y poderse encontrar así con la reina, con la que una vez más disfrutará de unos breves, pero intensos instantes de amor, sobre los que los textos que analizamos no son muy solícitos en información, pues con dichos instantes de amor y unión por parte de Tristán e Iseo se clausuran ambas Folies.

Si ya decíamos que el disfraz que Tristán había elegido en la versión de Béroul para encontrarse con Iseo y ayudarla en la treta del juramento de la Blanca Landa, el de leproso podía dar más información sobre la verdadera identidad de Tristán de lo que en un principio se pudiera pensar, el disfraz que Tristán adopta en las Folies, el de loco, es si cabe, mucho más clarificador sobre su verdadera personalidad. En efecto, múltiples eran las causas que se daban para justificar la enfermedad de la locura y, entre ellas, Blakeslee señala la del amor desa-

${ }^{27}$ M. L. Ollier, Op.cit., p.304.

${ }^{28}$ Esta idea en la que identidad y alteridad no son más que una en el personaje de Tristán ya la hemos señalado en un estudio dedicado a las Folies Tristan y sobre ellos apuntamos: "Su nuevo disfraz no es tanto una máscara en la que Tristán se esconde como sí un perfecto espejo que deja ver a la sociedad la imagen de una nueva identidad alterada, aquella que Tristán presenta desde que ingiere el filtro de amor" (R. GARCÍA PRADAS, "Cuando identidad y alteridad se convierten en una identidad alterada: el caso de las Folies Tristan", en M. ALFARO y P. SUÁREZ (eds.), L'autre et soi-même, Madrid (Universidad Autónoma de Madrid), 2003, p.747. 
fortunado: In twelfth-century secular literature, unhappy or unconsummated love was conventionally depicted as a wasting, mortal illness and as a cause of madness ${ }^{29}$. En este sentido, bien podemos reconocer que el amor que Tristán siente hacia la reina Iseo es un amor desafortunado. Desde el principio, su pasión ha sido producto de la fatalidad y, además, todo parece estar en contra de que este amor pueda realizarse, al menos de cara a la sociedad. Asimismo, esta pasión, como igualmente señala Blakeslee ${ }^{30}$, sumerge al héroe, desde el momento mismo en que la padece al ingerir el filtro de amor, no sólo en el desorden moral sino en el desequilibrio de sus facultades racionales, aspecto que, por ejemplo, se pone de manifiesto en ambas Folies cuando Tristán osa desobedecer el mandato de Marco, pese a saber que ello le puede costar la vida. Ello nos permite afirmar entonces que Tristán ya estaría loco antes de simular su locura ante Iseo y la corte de Marco. En base a ello, pensamos que cuando Tristán decide disfrazarse de loco para reunirse con Iseo no hace más que exteriorizar las repercusiones de un dolor que hasta entonces sólo ha podido vivir en su fuero interno, debido, principalmente, a la alineación social y a la soledad sentimental en las que fortuitamente se ha visto sumido ${ }^{31}$. Se trata, pues, de una locura lúcida en la que Tristán, mediante su disfraz, no hace otra cosa que asumir lo que verdaderamente $\mathrm{es}^{32}$.

Puesto Tristán a representar su papel, en ambos textos lo hace con una gran maestría, como ya veremos, y ello se comprueba una vez más tanto en su discurso como en su indumentaria. Conocedor de que la locura debía quedar delimitada a través de unos rasgos distintivos físicos, dada la marginalidad de la que el loco es objeto, Tristán se atavía con algunos de sus signos más representativos. Decide así cubrir su cuerpo con ropa envejecida y hecha jirones, pues tal era el hábito del loco medieval ${ }^{33}$. Asimismo, Tristán corta su rubia melena y se hace la tonsura con forma de cruz, rasgo que también visibilizó du-

${ }^{29}$ M.R. BLAKESLEE, Op.cit., p.76.

${ }^{30}$ M.R. BLAKESLEE, Op.cit., p.76.

${ }^{31}$ R. GARCÍA PRADAS, "La locura como metáfora de lo antisocial en las primeras versiones del Tristán: de su apariencia a su funcionalidad en la Edad Media”, en Cuadernos de Filología Francesa 14, 2002, 151.

${ }^{32}$ Este punto de vista es compartido por autores como Payen, quien, acerca de este aspecto, nos dice sobre Tristán: Il va se déguiser et son déguisement s'impose. En choisissant l'habit d'un fou, Tristan redevient ce qu'il est: il asume lucidement sa folie en revêtant le rôle qu'il lui est le plus facile de jouer (J-C. PAYEN, "Tristan, l'amans-amens et le masque dans les Folies", en D. Buschinger (ed.), La légende de Tristan au Moyen Âge, Göppingen (Kümmerle Verlag), 1982, p.62.

${ }^{33}$ P.MENARD, "Les fous dans la société médiévale. Le témoignage de la littérature au XII ${ }^{\mathrm{e}}$ et au XIII ${ }^{\mathrm{e}}$ siècle", Romania, XCVIII, 1977, 435. 
Daniel Grégorio

rante la Edad Media la marca de la locura al tiempo que servía, según nos dice Fritz, como "un moyen d'affaiblir leur force physique (celle des fous) (d'après l'histoire de Samson et Dalila)"34. Para completar su caracterización, Tristán embadurna su rostro con una hierba que se lo oscurece. Por otra parte, la habilidad de Tristán como actor también le permite incluso cambiar su voz:

Tristan unes forces aveit

K'il meïsmes porter soleit.

De grant manere les amat:

Ysolt les forces lu donat.

Od les forces haut se tundi:

Ben semble fol u esturdi.

En après se tundi en croiz.

Tristan sout bien muer sa voiz.

Od une herbete teinst sun vis

K'il aporta de sun païs;

Il oint sun vis de la licur

Puis ennerci, muad culur:

$N$ 'aveit hume ki al mund fust

Ki pur Tristan le coneüst,

Ne ki pur Tristan l'enterpast,

Tant nel veïst u escultast.

Il ad d'une harie un pel pris

E en sun col l'en ad il mis ${ }^{35}$.

A esta caracterización hemos de añadir el célebre bastón del loco, que le sirve como punto de apoyo en su continuo deambular y como arma de defensa cuando era objeto de escarnio por parte de las gentes del pueblo y que Tristán también toma, según nos dice la Folie de Berna: En sa main porte une maçue; Comme fox va: chascuns lo hue,/ Gitant li pierres a la teste $e^{36}$.

El disfraz de Tristán es perfecto, pero no sería nada si nuestro héroe no se metiera en el papel que en esta ocasión le tocará representar ante Marco y su corte y, una vez más, Tristán lo hace a la perfección, tal y como ambas Folies ponen de manifiesto.

\footnotetext{
${ }^{34}$ J.M. FRITZ, Le discours du fou au Moyen Âge, París (PUF), 1992, p.39.

${ }^{35}$ Folie d'Oxford, Op.cit., p.271.

${ }^{36}$ Folie de Berne, Op.cit., p.251.
} 
En la Folie de Berna dice llamarse Picous ${ }^{37}$ y ser hijo de una morsa y una ballena. La marca de la sinrazón queda, pues, puesta de manifiesto desde el principio de su discurso. Sin embargo, Tristán, en medio de su mentira y su farsa, osa proponerle un intercambio al rey, darle a su hermana Brunehaut a cambio de que Marco le entregue a Iseo. Su disfraz le da libertad para hacer una proposición de tal envergadura, pero no hemos de perder de vista que Tristán parece ser conocedor de las prerrogativas de las que gozaba el loco de corte, que, a menudo, con su cúmulo de despropósitos actuaba de bufón para los más pudientes. De ahí que llegue incluso más lejos cuando osa decir a Marco que es Tantris, el juglar por el que Tristán se hizo pasar para poder curarse en tierras de Irlanda de la herida causada por la lanza envenenada de Moroldo, según nos dicen las versiones de Eilhart o Gottfried von Strassbourg. Deducimos que el rey debía ser conocedor de este episodio, pero Tristán, en su puesta en escena y en la mentira de su identidad, continúa diciéndole al rey otras verdades sobre los momentos de intimidad que ha vivido junto a Iseo. Le recuerda así, por ejemplo, el momento en que Marco los sorprende juntos durmiendo en el bosque y dirigiéndose a la reina, quien aún no lo ha reconocido, le muestra el anillo que ella antaño le entregara, llegando así a tachar a su marido de cornudo:

\author{
Dame, cil cox ait mal dahé! \\ Së estoiez certe de moi, \\ Se près vos m'avoiez, ce croi, \\ Et vos saüssiez bien mon estre, \\ Ne lo commandemant lo roi. \\ Encor ai l'anel près de moi \\ Qui me donastes au partir \\ Del parlement que doi haïr: \\ Maldite soi ceste asanblee! $!^{38}$.
}

${ }^{37}$ Para J.M. TELFER, ("Picous: Folie de Berne”, French Studies, 5 1951, 60), el origen de tal nombre puede tener dos interpretaciones: la primera es que en los ciclos épicos se liga el nombre de Picous con la figura de un mago enano y la segunda es que, en tierras normandas, se atestigua en el siglo XII la existencia de un tal Willelmus Picol, loco que con sus gracias entretuvo al rey. Telfer parece adherirse más bien a esta segunda hipótesis para justificar la elección del nombre de Picous por parte de Tristán: It seems to me most likely that it was the fool, William Picol, who was the historical character, the point of departure, for this name.

${ }^{38}$ Folie de Berne, Op.cit., pp.253-254. 


\section{Daniel Grégorio}

No olvidemos que estas palabras están dichas teóricamente por un loco, es decir, por aquel que representa la sinrazón y que Tristán ha escondido muy hábilmente su verdadero rostro. Por tanto, puede permitirse el lujo de hablar de sí mismo sin que nadie tenga que ligarlo con su verdadero referente. Es más, en esta ocasión en la que, a diferencia de lo que ocurría en Béroul con la escena del escondit, no hay trato alguna con la reina, ni siquiera la propia Iseo es capaz de reconocer bajo su nueva máscara, pese a la clarividencia de sus palabras y pese a las no pocas pruebas que le ofrecerá, relatando, en forma de continuas analepsis, a la reina su historia de amor y los momentos más intensos de la misma, a su fiel amante Tristán, aspecto que se hace aún más acusado, si cabe, en la Folie de Oxford. En esta última versión, sin embargo, Tristán es más directo. Así, cuando Marco le pide que le desvele su identidad, Tristán no dice ni siquiera ser Picous sino que directamente se define como Tantris. Sólo bastaría alterar el orden de estas dos sílabas para darse cuenta de que es Tristán, aspecto que además se hace esperable si escuchamos la cantidad de pruebas que da a la corte y, en especial, a la reina sobre su verdadera identidad. Por otra parte, cuanto más fiel es la verdad que cuenta el supuesto loco, más toman los allí presentes tal discurso por mentira, especialmente la reina Iseo, quien en esta versión (Folie de Oxford) se muestra aún más incrédula, pero no hemos de olvidar, y repetimos una vez más, que Tristán es un actor perfecto. No en vano, en su primer encuentro con la corte, se ha encargado de escenificar perfectamente su papel de loco. Así, la mentira de la identidad que constituye su disfraz y, por ende, su doble, le permite de cara a la sociedad decir verbalmente la verdad sobre su identidad. Veamos en sendas Folies cómo Tristán ha jugado hábilmente su papel en esta primera escena de contacto para poder pasar, sin temor a sufrir represalia alguna, de la sinrazón a la razón, de lo absurdo a lo real o de la mentira a la verdad:

Li fols respunt: Ben vus dirrai

Dunt sui e ke je ci quis ai.

Ma mere fu une baleine.

En mer hantat cume sereine.

Mès je ne sai u je nasqui.

Mult sai jo ben ki me nurri.

Une grant tigre m'aleitat

En une roche u me truvat.

El me truvat suz un perun,

Quidat que fusse suz un perun, 
Si me nurri de sa mamele ${ }^{39}$.

Fox, com a nom? -G'é non Picous.

- Qui t'angendra? -Uns valerox.

- De que t'ot il?-D'une baleine ${ }^{40}$.

A modo de conclusión, y tal y como se desprende del estudio del tema del doble que en este artículo analizamos, las diversas puestas en escena que bien los dos amantes o bien Tristán solo llevan a cabo dan perfecta cuenta de la dificultad de establecer una barrera clara entre la verdad y la mentira. Como ya hemos dicho, buena parte de las mentiras que los amantes cuentan en el relato no son sino formas veladas y sutiles de decir la verdad. Tristán e Iseo buscan en todo momento jugar con todos los elementos que constituyen el acto de comunicación: el lenguaje, la imagen, el contexto, el referente, el destinatario, etc. Por otra parte, la propia repetición de un determinado mensaje genera en no pocos casos el efecto de verdad que se buscaba en el destinatario. Del mismo modo, la ambivalencia de la palabra también favorece a los amantes. Se podría decir que en esta historia de amor y fatalidad la mentira lo corrompe todo, empezando por el lenguaje y terminando por los personajes o por el propio narrador. No sólo Tristán e Iseo mienten sino que casi el resto de personajes que van desfilando a lo largo de la historia no quieren otra cosa que oír la mentira, para lo cual mienten incluso ellos mismos. Podríamos pensar en Dinas, en el ermitaño Ogrín, que termina por convertirse en cómplice de la mentira de los amantes, pese a lo que en teoría representa, en Brangien, la fiel sirvienta de Iseo, o en el propio rey Marco, quien en su fuero interno siempre anhela creer en la inocencia de los dos jóvenes, su sobrino y su esposa, mientras en alguna ocasión enciende su cólera contra el enano Frocin o contra los barones felones cuando le son portadores de una verdad que no quiere ver ni escuchar o, incluso, en última instancia, en Dios mismo, por quien los amantes juran su inocencia y quien parece protegerlos por encima de todo, como da perfecta cuenta de ello la versión de Béroul. Los textos tristanianos nos muestran, pues, que no existe tanto la verdad como sí la ilusión de la verdad, ilusión que en las distintas versiones analizadas se manifiesta en un complejo juego de puestas en escena donde nuestros amantes se desdoblan como si de actores se trataran para jugar su propio papel dentro de la historia y, en especial, Tristán, a quien la alienación que sufre desde que es expulsado de Cornualles crea una fisura, un desdoblamiento y

\footnotetext{
${ }^{39}$ Folie de Oxford, op.cit., p.273.

${ }^{40}$ Folie de Berne, Op.cit., p.252.
} 


\section{Daniel Grégorio}

una obligación de ser otro para poder ser él mismo junto a la reina, para obedecer a las exigencias que le impone su amor sin ser él y siendo más que nunca él mismo, el eterno enamorado de Iseo, el héroe que por amor pierde su honor y su propia identidad. 